\title{
DO ESGOTAMENTO REVOLUCIONÁRIO À LIBERALIZAÇÃO: o movimento sindical face às privatizações em Moçambique na década de 1990
}

\author{
Fernando Bessa Ribeiro*
}

\begin{abstract}
O artigo tem como objetivo a análise da posição do movimento sindical moçambicano face às privatizações ocorridas nesse país da África austral na década de 1990. Desenvolvendo um argumento fortemente escorado na história, a compreensão da incapacidade do movimento sindical em se opor de forma eficaz a esse processo tem de considerar o seu trajeto em Moçambique desde as suas origens, pósSegunda Guerra Mundial, e o do país, nomeadamente pós-independência, marcado pela guerra civil e a derrota do projeto revolucionário. Os dados foram recolhidos através de entrevistas em profundidade a dirigentes sindicais e responsáveis políticos e consulta de fontes documentais em arquivos moçambicanos. Como principal conclusão, indica-se que o fracasso do movimento sindical, na sua luta contra as privatizações, deveu-se à articulação de diversas causas, com destaque para as que se relacionam com sua escassa autonomia em relação à Frelimo, o "partido-Estado".
\end{abstract}

Palavras-chave: Movimento Sindical. Privatizações. Estado. Política. Liberalização.

\section{INTRODUÇÃO}

Ganha a independência em 1975, o Estado moçambicano procurou implementar um programa político radical, visando à alteração profunda das estruturas sociais, econômicas e simbólicas do país. Colocado na "linha da frente" da luta contra o apartheid, atrás do qual se camuflavam alguns dos principais interesses do imperialismo norte-americano - mormente os que se relacionavam com a contenção daquilo que o regime racista designava por "ameaça comunista” na África Austral -, Moçambique travou uma longa e dolorosa guerra civil que deixou o país exausto e acabaria por liquidar o próprio processo revolucionário, conquanto as suas experiências e aspectos mais positivos tenham produzido efeitos resilientes para a imaginação de novos projetos emancipatórios.

Abrindo com a discussão das causas desse colapso, o texto reflete acerca da posição

* Universidade de Trás-os-Montes e Alto Douro, Escola de Ciências Humanas e Sociais. Universidade do Minho, Centro de Investigação em Ciências Sociais.

Rua: Dr. Manuel Cardona, 5000-558. Vila Real - Portugal. fbessa@utad.pt do movimento sindical face às privatizações, decorridas já duas décadas desde o seu arranque. Se é certo que o foco da discussão se centra na década de 1990, durante a qual ocorre a larga maioria das privatizações, em especial do setor industrial, não se obnubila as décadas anteriores, uma vez que elas são cruciais para se compreenderem as razões fundas das posições assumidas pelo movimento sindical ao longo desse processo. Daí que parte do texto seja ocupada com a apresentação crítica do trajeto do sindicalismo em Moçambique, desde a sua criação ainda antes da Segunda Guerra Mundial e em pleno período de consolidação da presença colonial portuguesa em África.

\section{O FRACASSO DA EXPERIÊNCIA RE- VOLUCIONÁRIA}

Em 1983, às vésperas do IV Congresso da Frelimo, era já nítido que "a década do desenvolvimento" não se concretizaria, arrastando consigo o projeto socialista de transformação radical da sociedade moçambicana. O relatório do Comité Central (CC) apresentado ao con- 
gresso fazia um diagnóstico que, no essencial, inventaria com rigor os problemas com que o país se defrontava (Relatório do Comité Central ao IV Congresso, 1983). Nem todos eram consequência da guerra que o país enfrentava: destacavam-se os problemas relacionados com a comercialização agrária e, em particular, o menosprezo do setor familiar, a secundarização da iniciativa local e dos pequenos projetos, a centralização excessiva das decisões, marginalizando os cidadãos e, no domínio das empresas, a escassa participação dos trabalhadores na tomada e no controle das decisões. O relatório denunciava ainda a existência de uma camada social que, avessa à participação dos trabalhadores na gestão da produção, entre outros aspectos, aspirava a transformar-se em burguesia. Para Hanlon (1996, p. 198), eram numerosos os burocratas e dirigentes do partido interessados em desenvolver novos estilos de vida, de tipo ocidental, que apenas poderiam ser alcançados pela mudança de posição de classe. Durante o congresso, muitos delegados falaram da completa desarticulação da estrutura produtiva, do crescimento explosivo do mercado negro - a "candonga" - e da enorme crise no sector agrícola, do roubo e do desleixo em muitas unidades industriais (Intervenções dos delegados ao IV Congresso, 1985). apresentadas e aprovadas pelos delegados, a luta contra a fome e o aumento da produção emergiam como objetivos prementes. Para realizá-los, foi definido um conjunto muito vasto de medidas, no qual sobressaía o papel atribuído à iniciativa privada nos três setores econômicos, colocada praticamente a par das outras formas de organização da produção. Esperavase, assim, expandir a produção, melhorar a circulação e distribuição de mercadorias, aumentar as exportações e a substituição das importações, recorrendo-se, sobretudo, à participação do capital estrangeiro. No plano da cooperação internacional, é relevante a colocação de todos os países no mesmo patamar, sem qualquer referência às relações com o bloco socialista. Para
Wuyts (1990, p. 105-109), a imperativa necessidade de se incrementar a produção desvalorizou o modo como ela deveria ser conseguida. Sabendo-se que a acumulação privada através dos mercados paralelos - a referida "candonga" - detinha uma enorme força econômica e influência social, o caminho escolhido foi o da liberalização. Desse modo, dava-se satisfação às críticas daqueles que viam como principais constrangimentos ao incremento da produção “[...] a concentração dos recursos no setor estatal, combinada com uma confiança excessiva na regulamentação do comércio" (Wuyts, 1990, p. 105). Para muitos dirigentes e, sobretudo, para a população em geral, repetindo uma situação comum a outros países africanos em ajustamento estrutural, tratava-se de perseguir o objetivo por outros meios:

Para a maioria das pessoas, no entanto, a opção pelo "mercado" não implica nenhuma mudança de objetivo. Na década passada, povos de África (e de toda a parte) voltaram-se para o "mercado" buscando exatamente o mesmo que antes buscavam no "Estado". O que eles esperam conseguir é aquele eldorado fugidio chamado "desenvolvimento" (Wallerstein, 2002, p. 71).

O fim da concordância entre as práticas políticas e o discurso teórico-ideológico terá sido um recuo para, mais à frente, retomar o caminho socialista ou um abandono efetivo dele, como desejavam os países ocidentais? Ou, num registro bem diferente, terá o congresso estabelecido as condições para o aprofundamento do socialismo? Essa é a tese de Egerö (1992, p. 126-128), ao sustentar que dele saíram as medidas necessárias ao que alguns autores definiram como o terceiro estágio da transição socialista na periferia: a reintrodução de mecanismos de mercado e o apoio à participação do setor privado em todos os setores da economia, de modo a estabelecer o "socialismo de mercado" (Roemer, 1994). Para Abrahamsson e Nilsson (1994, p. 221-223), os defensores dessa última posição interpretavam as medidas a favor da pequena agricultura familiar, decididas pelo IV Congresso, como um 
restabelecimento da aliança histórica que unia a Frelimo aos camponeses, da qual dependia o projeto socialista moçambicano. Ora, como os autores justamente salientam, nem o campesinato é um grupo homogêneo, nem, acrescentese, ele tinha um interesse objetivo nas relações de produção socialistas.

Já as organizações de massas, como a Organização da Juventude Moçambicana (OJM), a Organização das Mulheres Moçambicanas $(\mathrm{OMM})$ e, mais tarde, a Organização dos Trabalhadores Moçambicanos - Central Sindical (OTM-CS), não possuíam autonomia em relação ao Partido-Estado. Em vez de constituírem espaços de expressão do poder popular, eram "correias de transmissão" daquele, desempenhando funções importantes no controle social. Se é certo que, como salienta Roesch (1992, p. 31), o país se defrontava com a inexistência de uma classe operária desenvolvida, um enorme analfabetismo, a herança colonial e a guerra de desestabilização, é preciso relevar também o papel desempenhado pelo modelo organizativo adotado pela Frelimo. Baseada numa concepção profundamente deformada do centralismo democrático, a prática política quotidiana ficou marcada pela concentração do poder na cúpula do aparelho partidário e no chefe de Estado, fazendo-se sentir a "personalização do poder", presente também em outros Estados de orientação socialista (Tchírkine et al, 1983).

A restauração capitalista foi facilitada pelo fato de a dependência em relação aos países capitalistas nunca ter sido quebrada. Herdando uma estrutura econômica colonial orientada para o fornecimento de matérias -primas e produtos industriais ao Ocidente, a rutura nunca foi concretizada, apesar do estabelecimento de relações privilegiadas com o bloco socialista. Na perspetiva controversa de Wallerstein (1998, p. 79), os Estados revolucionários da periferia, a própria União Soviética e seus aliados do leste europeu, não constituíam “[...] uma estrutura externa ao sistema histórico [capitalista], mas um produto dos seus processos internos". Não tendo existido um sistema mundial alternativo, esses Estados continuaram subordinados aos países capitalistas centrais e muito vulneráveis, como atempadamente reconheceu o poder frelimista, aos "efeitos de crise económica internacional do capitalismo" (Relatório do Comité Central ao IV Congresso, p. 8). A recusa da entrada de Moçambique no Comecon (Outono de 1982), acompanhada pelas dificuldades crescentes da União Soviética, fez os dirigentes moçambicanos compreenderem que o bloco socialista não podia fornecer os recursos (e as rendas) de que o país e as elites precisavam (Abrahamsson e Nilsson, 1994, p. 64). Os contatos diplomáticos e a cooperação com os países capitalistas acentuaram-se. Em 1984, Moçambique assina a Convenção de Lomé, submetendo-se às condições apresentadas pela hoje designada União Europeia, e adere aos acordos de Bretton Woods, adesão justificada pela promoção da "cooperação bilateral e multilateral com todos os países, independentemente do seu regime económico e social” (Decreto n. ${ }^{\circ}$ 6/84 de 19 de Setembro).

\section{A LIBERALIZAÇÃO EM MARCHA}

Com um endividamento externo imenso e as receitas de exportação a representarem apenas 14,5\% do serviço da dívida, "a posição negocial de Moçambique não era muito forte" (Roesch, 1992, p. 10-11). Os planos de ajustamento e recuperação econômicos são consequência direta desse cenário. Essa agenda neoliberal iria exigir a liquidação das empresas estatais e do setor público moçambicano. O destaque vai, naturalmente, para a Caju de Moçambique, a maior empresa moçambicana, com um peso enorme na economia e nas exportações do país. O Plano de Reabilitação Económica (PRE) foi o primeiro plano. Negociado pelo governo moçambicano junto ao Fundo Monetário Internacional (FMI) e ao Banco Mundial (BM) e começou a ser executado em Abril de 1988. Como sustenta Wuyts (1990, p. 100), o PRE resultou de necessidades 
internas, relacionadas com a guerra e o declínio da produção, e das exigências dos credores das instituições internacionais e dos países ocidentais, apresentadas como fundadas em exigências técnicas. Se é certo que o PRE conseguiu obter alguns resultados econômicos positivos imediatos - aumento do PIB, das exportações e de um muito ligeiro aumento da produção industrial -, eles ficaram muito aquém das expectativas enunciadas pelos peritos a ele ligados (Roesch, 1992 e Hanlon, 1996 99). Em 1991, os sinais do seu fracasso eram já bem evidentes. Como reconheceu o então primeiro-ministro Mário Machungo, “[...] em 1990 a atividade econômica não cresceu ao mesmo ritmo que a dos anos 1987 e 1988 [...]”, ficando marcada pela queda na indústria e nas pescas, bem como por uma diminuição efetiva dos rendimentos salariais com a concomitante redução do consumo per capita da ordem dos 3\% (Tempo, n. ${ }^{\circ} 1085$ de 4/8/1991). ${ }^{1}$

Prosseguindo com sua estratégia de liberalização da economia moçambicana, o BM avançou em meados da década de 1990 para o setor do caju, o mais importante da economia moçambicana. Daí que a sua privatização fosse essencial para o efetivo restabelecimento de uma economia de mercado. Sujeito, desde os anos de 1950, a uma intervenção regula$\stackrel{2}{5}$ dora do aparelho estatal, esse setor encontra․ va-se excessivamente "protegido" na ótica do pensamento neoliberal. Não bastava privatizar as fábricas, havia que liberalizar a cadeia comercial, desde o produtor até à exportação da castanha em bruto, acabando com todos os mecanismos administrativos de definição de + preço, abastecimento da indústria e restrições a fiscais à comercialização nos mercados inter$\stackrel{\infty}{N}$ nacionais. Por outras palavras, tratava-se de $\vec{s}$ estabelecer uma nova política para o setor do caju, com a liberalização da exportação da castanha in natura, rompendo, assim, com uma estratégia que se mantinha inalterada desde a segunda metade do século XX.

${ }^{1}$ Na década de 1980 , a revista Tempo era a publicação não acadêmica de maior prestígio em Moçambique.
O processo é bem conhecido, tendo merecido o acompanhamento da mídia (entre outros, o Metical, n. ${ }^{\circ} 111$ de 1/12/1997 e AIM, de 2/2/1999). O BM impôs ao governo moçambicano, no âmbito do Country Assistance Strategy (CAS), a introdução de medidas liberalizadoras para a exportação de castanha de caju, através da redução da sobretaxa aplicada de $26 \%$ para 20\% em 1995, devendo ela desaparecer completamente em 1999. ${ }^{2}$ Do contrário, não liberaria os créditos de que o país carecia para a reconstrução, no valor de 400 milhões de dólares. Sendo certo que o governo moçambicano foi sujeito a uma forte pressão, sob a ameaça da asfixia financeira, importa salientar também que o BM contou com os seus aliados locais, não raro dele dependentes como consultores. De fato, desde a segunda metade dessa década, a influência dos técnicos moçambicanos licenciados e pós-graduados nos Estados Unidos era bem visível. Agindo como "cavalos de Troia" do neoliberalismo, marcam presença em todos os ministérios, onde lhes cabe uma parte substancial do trabalho de organização e preparação de relatórios e outros documentos essenciais à tomada de decisões políticas por parte dos titulares das pastas. Nas inúmeras publicações acadêmicas e de opinião, muitas delas baseadas em investigações financiadas pela United States Agency for International Development (USAID), e nas intervenções públicas, mesmo ressalvando que elas não vinculam o ministério, as teses neoliberais são defendidas com veemência. Assim, em Moçambique, nada foi feito sem que, antes, as missões e os consultores apresentassem seus estudos e relatórios, cujas conclusões concordam sempre com as teses neoliberais defendidas pelos seus empregadores. ${ }^{3}$ Saliente-se que a retórica

${ }^{2}$ Proibida desde 1975, a exportação de castanha foi autorizada a partir de 1991 (v. J. P. Leite, 2000).

${ }^{3}$ No caso do caju, o relatório de Hilmarsson (1995) é ilustrativo. Consultor do BM foi contratado para legitimar, com a manipulação mais ou menos hábil de dados empíricos, os pressupostos do modelo econômico hegemônico. Tendo visitado Moçambique em meados de 1994, integrado numa missão do BM, o seu trabalho foi incluído num relatório geral publicado em 1995 sobre impedimentos para a recuperação do setor industrial moçambicano. 
liberalizadora é disfarçada por uma pretensa neutralidade. Como esclarece Stiglitz (2003), as decisões do $\mathrm{BM}$ e das demais organizações do Consenso de Washington são formuladas com base numa mistura de ideologia e fundamentos econômicos medíocres. O desencorajamento ostensivo da discussão aberta não impede somente o questionamento das decisões e opções tomadas, pois parece também atuar como mecanismo de ocultação dos interesses dominantes aos quais as organizações estão submetidas.

Em suma, Moçambique abria-se à economia de mercado com uma nova classe burguesa conectada estreitamente com o aparelho de Estado. Os novos capitalistas são antigos membros do governo ou ex-gestores das empresas estatais. Uns e outros se serviram de seus contactos privilegiados no aparelho de Estado para adquirir o controle das fábricas e de outras unidades de produção alienadas (Pitcher, 2003, p. 813). Muitos desses detentores de capital continuaram a circular pelo aparelho estatal, não deixando de condicioná-lo e utilizá-lo como um instrumento de extração de recursos e, por outro lado, como garantia da ordem política e social na qual medram, explorando, com habilidade, a falta de transparência da administração pública, um dos aspetos mais marcantes do Estado em África (Milando, 2003, p. 51).

\section{A RESPOSTA SINDICAL ÀS PRIVA- TIZAÇÕES}

Em 1992, estavam já paralisadas ou em funcionamento intermitente muitas empresas estatais. Do extenso rol podem-se mencionar a Cometal-Mometal (metalomecânica), a Suínos de Maputo, a Indel (eletrodomésticos) e, pela sua importância econômica e peso social, a Companhia Industrial da Matola (cereais) e numerosas fábricas da Caju de Moçambique. Em muitas delas, os salários deixaram de ser pagos, colocando em causa a sobrevivência dos operários e a reprodução social das suas famílias. A instabilidade laboral rapidamente se fez sentir, assumindo lugar de destaque as "greves" pelo pagamento dos salários em atraso. Esclareça-se que as greves não significavam a paragem do trabalho, pois ocorreram sempre em fábricas paralisadas. Embora designadas e assumidas como tal pelos trabalhadores e suas direções sindicais, estamos mais perante formas de protesto social assentadas em ocupação de fábricas e bloqueio de estradas, cujas principais reivindicações eram o pagamento dos salários em atraso e a retomada da laboração. Mas não só. Os trabalhadores pugnaram também pelo afastamento dos gestores públicos por eles considerados corruptos, pela saída dos dirigentes sindicais coniventes e pela defesa dos benefícios sociais colocados em causa pela liberalização (Tempo, n. ${ }^{0} 1.095$ de 13/10/1991, n. ${ }^{\circ} 1.142$ de 6/9/1992, n. ${ }^{\circ} 1.191$ de 19/09/1993 e n. ${ }^{\circ} 1.235$ de 21/08/1994).

As "greves" fizeram-se igualmente sentir na Caju de Moçambique, afetando diversas fábricas ao longo do ano de 1994, dando, assim, expressão aguda ao desespero de milhares de trabalhadores e suas famílias. Foram desencadeadas sempre localmente, por iniciativa dos trabalhadores, sem qualquer articulação com as outras fábricas da empresa e, em regra, à revelia da estrutura sindical. Essa estrutura, quando confrontada com o processo grevista em marcha, não deixou de apoiá-lo, mobilizando, para o efeito, os dirigentes locais e os nacionais fixados em Maputo. Os meses de Julho e Agosto de 1994 foram particularmente agitados. Entre os principais focos de descontentamento destacaram-se as greves em Inhambane (província de Inhambane) e em Manjacaze (província de Gaza). Em ambas, a causa principal prendia-se aos salários em atraso, incluindo os dos que estavam em casa, por falta de trabalho, a receber $70 \%$ do vencimento a que teriam direito se estivessem em atividade produtiva normal.

Como em quase todos os conflitos laborais ocorridos nos outros setores, e à semelhança do que fizeram os sindicatos que neles 
atuam, a direção nacional do Sindicato dos Trabalhadores da Indústria do Caju (Sintic) foi arrastada pela dinâmica dos processos reivindicativos. Para esse quadro concorria, por um lado, a excessiva tramitação burocrática dos mecanismos conducentes ao pré-aviso de greve, que torna "quase impossível a greve" (Boaventura Mondlane, antigo secretário-geral do Sintic, entrevista áudio), e, por outro lado, a ação constrangedora das direções das empresas, particularmente intensa durante o período das 72 horas do pré-aviso. ${ }^{4}$

As dificuldades em levar a cabo greves “organizadas" não se esgotam, porém, nesses embaraços legais. Não menos importante para o desfasamento entre a luta operária no terreno e os sindicatos eram as relações de dependência das suas direções em relação à Frelimo. Como noutras organizações, também essas possuem a sua história, cuja origem remonta aos momentos finais da presença colonial portuguesa. Durante o período de transição, os trabalhadores moçambicanos descobriram o "sabor" das reivindicações laborais em liberdade, incluindo a greve. À revelia dos sindicatos corporativos, completamente desacreditados, ocorreram, em 1974 e 1975, até a transmissão do poder para a Frelimo, numerosas ações reivindicativas que, em alguns casos, assumiram

농 a forma de greve. Quase sem exceção, todos $\stackrel{\sim}{\circ}$ os setores foram afetados, com destaque para $\stackrel{8}{\perp}$ as empresas industriais de grande dimensão. Nesse movimento de reivindicação laboral e social, participaram também trabalhadores

$\dot{a}$ portuguesa (Tempo, n. ${ }^{\circ} 195$ de 16/6/1974).

$\stackrel{\infty}{\sim}$ Estava aberto o caminho para a eventual for-

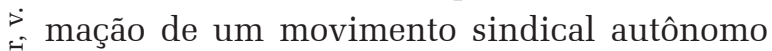
face ao Estado e ao patronato. ${ }^{5}$ Esse processo

${ }^{4}$ Na Lei n. ${ }^{\circ}$ 6/91 de 9 de Janeiro, Boletim da República - I Série. No art. ${ }^{\circ} 13^{\circ}$, pode-se ler que "durante o pré-aviso

de greve, o Ministério do Trabalho, por sua iniciativa ou a pedido da entidade empregadora ou do organismo sindi-

cal, poderá desenvolver as ações conciliatórias que julgar adequadas".

${ }^{5}$ Nessa discussão, é necessário notar que a sindicalização colidiu com a arquitetura político-jurídica que estruturava as relações de trabalho desde os anos 30 do século XX (figura 1). Descrevendo sucintamente os seus principais elementos, em 1933 foi aprovado o Estatuto do Trabalho Nacional [Diploma Legislativo (DL) n. ${ }^{\circ} 23.084$ (Diário do Governo de 23 de Setembro de 1933)], um dos pilares do Estado corporativo português, cujos princípios e outros elementos reguladores foram transpostos para as colônias em 1937, pelo DL n. ${ }^{\circ} 27.552$ (Diário do Governo de 5 de Março de 1937). Em 1943 e 1944, constituíram-se as primeiras organizações sindicais corporativas, respectivamente, o Sindicato Nacional dos Empregados do Comércio e Indústria e o Sindicato Nacional dos Motoristas e Ferroviários de Moçambique. Como salientam Hedges e Rocha (1999, p. 101), os sindicatos corporativos “... atuavam no sentido do enquadramento dos trabalhadores brancos no sistema [...]. Estreitamente controlados, não representavam grande perigo para a administração colonial”. Mais tarde, nos anos de 1950, o legislador procede a novas alterações, fixando com rigor as classificações das entidades patronais e dos trabalhadores, enquadradas nos sindicatos corporativos e respectivas remunerações mínimas [Diploma Legislativo 1.595 (DG de 28 de Abril de 1956) e as portarias de n. ${ }^{\circ} 11.459$ a n. $\left.{ }^{\circ} 11.476\right]$.

Sublinhe-se que essas ações reivindicativas e grevistas não deixaram de incorporar o descontentamento que se fez sentir nos primeiros anos da década de 1970, ainda antes da queda do regime ditatorial em Portugal em Abril de 1974, durante os quais foi já perceptível um forte descontentamento das classes trabalhadoras assalariadas em torno de questões como os baixos salários e a deficiente proteção social, em especial na doença e na reforma.

não era um direito universal em Moçambique. A ela tinham acesso os trabalhadores de escritório e dos serviços, comércio e indústria, os motoristas, os mecânicos de automóveis e de atividades conexas, os operários da construção civil e os ferroviários. Ou seja, o grosso dos setores onde se empregavam os assalariados brancos originários da metrópole, que beneficiavam, quando comparados com a maioria dos trabalhadores negros, de condições de trabalho e de remuneração substancialmente superiores. 
As críticas eram expostas abertamente por dirigentes sindicais, merecendo a cobertura da mídia (Tempo, n.os 46 e 47 de 1971), situação que tornava visível a crescente fraqueza do regime. Caído este, de imediato desponta, como foi dito, um movimento laboral que leva à radicalização dos sindicatos já existentes, muitas vezes implicando a demissão das direções em exercício e a constituição de novos em setores onde eles estavam proibidos, como o do funcionalismo público. Por uma ou outra via, esse movimento de trabalhadores deu os primeiros passos para a constituição de sindicatos autônomos face ao Estado. poderia ter contido os desvios burocráticos e a manutenção da influência operária e dos interesses das classes trabalhadoras na Frelimo e no Estado moçambicano. Contaminada pelo modelo político e social dito marxista-leninista, de raiz stalinista, formalmente institucionalizado no III Congresso realizado em 1977, a elite dirigente sufocou, num primeiro momento, essas iniciativas autônomas dos trabalhadores, para logo criar um movimento sindical a partir do topo, rigidamente controlado e fortemente subordinado à Frelimo e ao Estado. Guiados pela interpretação stalinista das teses de Lênin, os sindicatos foram transformados

Figura 1 - Linha cronológica do sindicalismo em Moçambique (1933-1999)

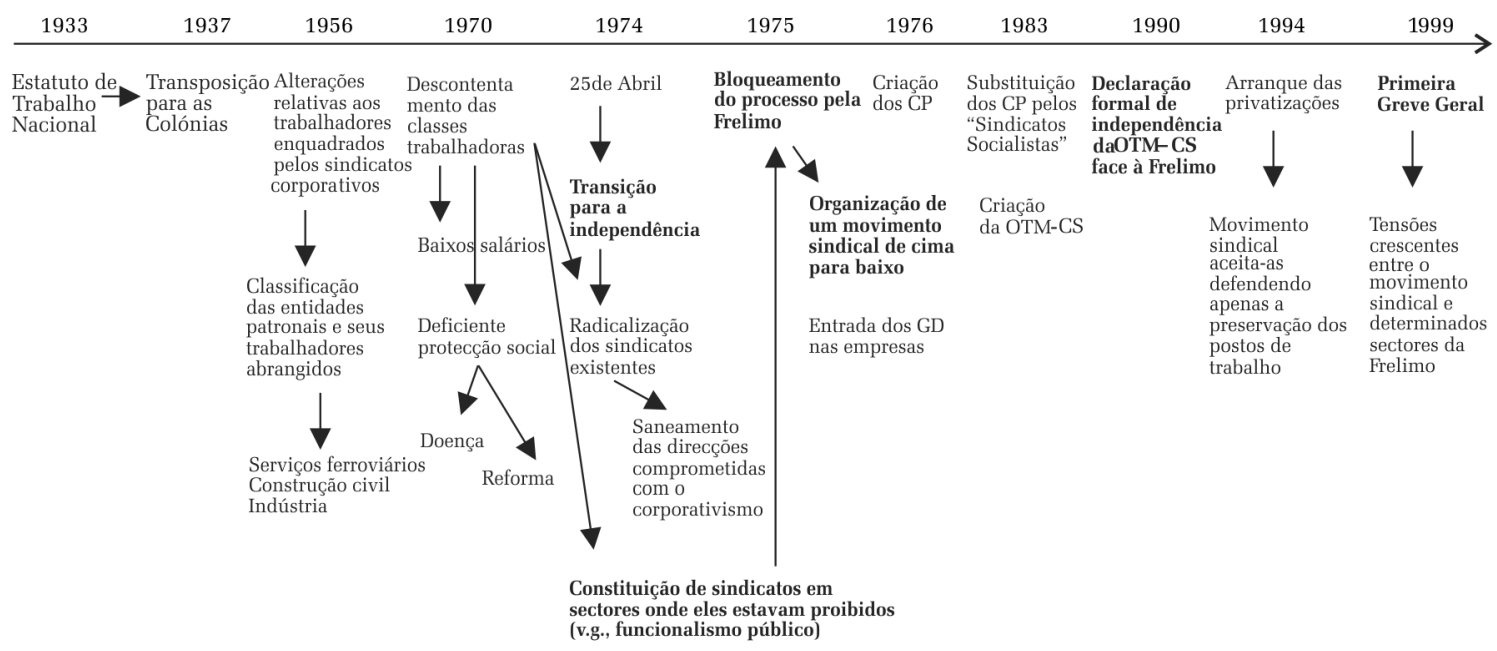

Com a Frelimo no poder, esse processo foi bloqueado, levando à asfixia das reivindicações sindicais que provinham das camadas trabalhadoras mais privilegiadas. De certo modo, elas estavam marcadas por um conteúdo trade-unionista que, a prazo, poderia conduzir a compromissos no quadro do capitalismo. Nesse contexto, existia também um risco sério de as direções dos sindicatos mais influentes ficarem sob o controlo das frações mais poderosas e engenhosas do patronato. Todavia, ao travar o processo, a elite dirigente liquidou todas as hipóteses de constituição de um movimento operário e de trabalhadores ativo, democrático e fiscalizador do próprio poder político. Ou seja, como hoje parece evidente, deitou fora o instrumento que melhor numa correia de transmissão do partido. ${ }^{6}$ Em

${ }^{6}$ A questão da subordinação do movimento sindical ao partido é uma velha discussão no campo marxista. A discórdia está ligada ao modelo organizativo e às relacões entre sindicatos e partido e não tanto à natureza da luta política e social. Quer dizer, é relativamente pacífico considerar que “... existe uma única luta de classe, tendo em vista simultaneamente limitar os efeitos da exploração capitalista e suprimir ao mesmo tempo esta exploração e a sociedade burguesa" [Luxemburgo 1970 (1906), p. 94]. As dificuldades se colocam na relação entre partido e sindicatos. Enquanto o leninismo amarra os sindicatos a uma férrea sujeição ao partido, a interpretação dada pela corrente revolucionária luxemburguesa aponta para a aceitação de certa autonomia organizacional e de interesses, uns mais políticos e de longo prazo, os do partido, outros mais econômicos e de curto prazo, os dos sindicatos, que, em contextos de ação revolucionária, imediatamente se devem dissolver num só. Nesse sentido, na avisada formulação de Luxemburgo [1970 (1906), p. 109], cujas críticas ao modelo leninista de organização do partido são bem conhecidas, "... não se trata, bem entendido, de destruir toda a estrutura sindical no Partido..." quando se coloca a exigência de articulação da ação do partido com os sindicatos. Para uma crítica severa à perspectiva leninista sobre os sindicatos e o papel do partido num estado operário, ver Brinton (1975). 
termos organizacionais, nomeadamente no domínio dos papéis a desempenhar pelo partido e pelos sindicatos, foi manifesta a influência de Stálin. A sua visão foi praticamente decalcada para Moçambique pela Frelimo:

[O partido] serve para coordenar o trabalho de todas as organizações de massa do proletariado, sem exceção, e para orientar a sua ação para um único fim: a libertação do proletariado [enquanto] os sindicatos, como organização de massa do proletariado, ligam o Partido à classe, principalmente no domínio da produção [Stalin, 1972 (1926), p. 37-38].

É certo que a jovem nação se debatia com dificuldades estruturais, designadamente uma pequena classe operária numa sociedade composta por uma maioria esmagadora de camponeses cujos interesses e objetivos estavam longe de coincidir com o programa político da Frelimo, e limites de organização e de consciência política que não eram superáveis em curto prazo e apenas a golpe de lei escrita e de ações voluntaristas. Isto é, em termos de interesses e expectativas de luta, as classes trabalhadoras moçambicanas pouco tinham a ver com suas congêneres nos países europeus e latino-americanos. Logo, dificilmente seriam viáveis alternativas democráticas radicais, sobretudo quando pensadas para outros contextos completamente distintos. Assim, é fatal reconhecer o papel inevitável do Partido-Estado, como "locomotiva" de um processo que visava à mudança das estruturas econômicas, acompanhada duma melhoria generalizada das condições materiais de existência da população. Em face disso, o problema se colocava, sobretudo, na aplicação mecanicista do modelo leז ninista, sem qualquer criatividade e segundo \& uma lógica que o validava ad aeternum, não $\stackrel{\infty}{\sim}$ dando praticamente folga alguma ao enraiza-

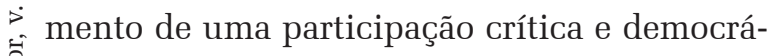
tica por parte dos trabalhadores.

A presença da Frelimo no espaço da produção começou com os Grupos Dinamizadores (GD). São eles que vão levar a cabo as iniciativas de propaganda e debate. Considerando que "[...] eram estruturas políticas e o seu papel tinha caráter mais de divulgação da política da Frelimo do que de organização dos trabalhadores" (Documento de circulação interna da OTM-CS, s.d.), foi decidido avançar para uma forma mais institucional de organização: os Conselhos de Produção (CP). O momento público de arranque do processo foi a intervenção de Samora Machel em 13 de Outubro de 1976, na Escola Secundária Josina Machel, num encontro com membros dos GD, na qual foi preconizada a constituição dos CP. Tendo por base o grande desígnio nacional o aumento da produção e da produtividade -, com eles se pretendia facilitar "[...] a participação ativa dos trabalhadores na planificação, gestão e controle da atividade produtiva [...] e combater eficazmente a sabotagem do inimigo e a indisciplina, incompetência e ignorância no seu próprio seio" (Relatório do Comitê Central ao IV Congresso, 1983, p. 143). ${ }^{7}$ Visava-se, mesmo, a objetivos mais profundos, relacionados com "[...] a gloriosa tarefa de transformar a atitude e o comportamento do homem explorado perante o trabalho, particularmente através da emulação socialista, da libertação da criatividade e do espírito inovador dos trabalhadores." (Tempo, n. ${ }^{\circ} 656$ de 8/5/1983). ${ }^{8}$

Em 1983, após sete anos de funcionamento, os CP tinham logrado uma larga implantação na esfera produtiva, abrangendo dez ramos de atividades, cerca de 6.000 empresas e quase meio milhão de trabalhadores, apesar de muitos de seus membros não compreenderem com rigor o papel que deviam desempenhar, devido à falta de formação e experiência política (Davies et al. 1980, p. 17). Na IV Reunião Nacional dos CP, Marcelino dos Santos afirmou: "[...] vocês cresceram e demonstraram ao longo desses anos um crescimento não só político, mas também na organização dos trabalhadores com vista à vitória segura na luta contra o sub-

${ }^{7}$ Apesar dessa clara distinção entre GD e CP, o poder político frelimista considerou sempre que ambas as estruturas eram instrumentos de classe portadores de objetivos e interesses comuns (ver Tempo, n. ${ }^{\circ} 341$ de 17/4/1977).

${ }^{8}$ Resolução sobre a criação dos sindicatos aprovada no IV Congresso do partido Frelimo (cf. Tempo, n. ${ }^{\circ} 656$ de 8/5/1983). 
desenvolvimento no nosso país." (Tempo, n. ${ }^{\circ}$ 652 de 10/4/1983). Para o Partido-Estado, tinha chegado o momento "para a passagem a um estádio superior de organização”, a se concretizar sob a forma dos "Sindicatos Socialistas na República Popular de Moçambique” (Relatório do Comité Central ao IV Congresso, 1983, p. 145), dando, assim, prosseguimento efetivo ao apontado pela alocução de Machel em 1979, na qual foi atribuída aos CP a tarefa de liquidar definitivamente a velha organização sindical corporativa montada pelo colonialismo, através da sua organização por setores de atividade (Tempo, n. ${ }^{\circ} 515$ de 24/8/1980).

O IV Congresso confirma essa intenção política, aprovando especificamente uma resolução sobre a criação dos sindicatos. Fechando essa fase, realizou-se, em Outubro de 1983, a "Conferência Constitutiva dos Sindicatos Moçambicanos", com a presença de cerca de três centenas de delegados provenientes de todas as províncias do país e, aspecto da maior relevância política, de membros do Bureau Político do CC da Frelimo, da Comissão Permanente da Assembleia Popular e do Conselho de Ministros. Obviamente, Samora Machel marcou sua presença com um discurso onde definiu as linhas políticas e ideológicas que deveriam orientar os sindicatos e a sua organização federativa, a OTM-CS. À contracorrente do processo de desmantelamento da natureza socialista do Estado moçambicano decidida pelo IV Congresso da Frelimo em 1983, Machel encamisou o novel movimento com os textos programáticos e, sobretudo, a retórica marxista-leninista do partido, na qual a luta contra a fome e a nudez assumia, por um lado, um caráter político concreto e, por outro, apresentava uma justificação compreensível para os trabalhadores sobre a existência dos sindicatos:

Os Sindicatos são a forma de organização das classes trabalhadoras moçambicanas na fase em que construímos o socialismo. As tarefas dos Sindicatos, sendo igualmente tarefas patrióticas, têm um conteúdo de classe mais profundo, têm um conteúdo socialista. Sob a direção do Partido Frelimo, os Sin- dicatos organizam os trabalhadores moçambicanos para a realização das grandes tarefas definidas pelo $4^{\circ}$ Congresso. Os Sindicatos serão, fundamentalmente, o nosso grande exército para a guerra que travamos contra a fome e a nudez. Serão o exército do Partido na guerra contra o subdesenvolvimento. [...] Os Sindicatos Socialistas serão a forja de consciência de classe dos trabalhadores moçambicanos. Serão a fábrica que produzirá a ideologia revolucionária do proletariado, o marxismo-leninismo. (Machel, 1983, p. 33-38).

Nesse quadro, não poderia ter surgido nada diferente do que efetivamente surgiu: sindicatos e uma central sindical, criados de cima para baixo, agrilhoados aos interesses da elite do Partido-Estado que controlava os dirigentes sindicais, os métodos de funcionamento e os próprios recursos financeiros (Moyana, 1993, p. 25). Mais: entre o partido e a OTM-CS e os seus sindicatos, estabeleceram-se vias de circulação de dirigentes. Progressivamente, dando expressão concreta à descoincidência de interesses e objetivos, uns e outros se afastaram dos cidadãos e dos trabalhadores. Nisso entroncam as causas profundas do que se viria a passar, mais tarde, com as privatizações. Completamente dependente do partido, autêntica "correia de transmissão", segundo a concepção leninista, o movimento sindical rapidamente foi contagiado pelos fenômenos da burocratização e da autocracia que dominavam a vida política moçambicana. ${ }^{9}$ Quando a direção frelimista impôs a liquidação do aparelho produtivo estatal, a elite sindical foi incapaz de reagir e de acompanhar o vivo sentimento de desconfiança dos trabalhadores que representavam e deviam defender. Não raro, os dirigentes sindicais afastaram-se das lutas travadas pelas bases. Se, formalmente, nada atava a OTM-CS ao Partido-Estado - desde o seu II Congresso, a organização sindical havia declarado sua independência em relação ao poder político, aos

${ }^{9}$ Esclareça-se que esses fenômenos não eram desconhecidos no mundo do trabalho. De fato, manifestou-se nos CP, como lucidamente denunciou Machel (1983, p. 40), ao exigir a máxima atenção dos sindicatos relativamente "ao perigo de caírem num estilo de trabalho autoritário ou burocrático". 
partidos e ao patronato ${ }^{10}$-, na prática, assim não sucedia. Com efeito, sabemos bem que as relações de dependência e as lógicas clientelistas não se removem por um golpe jurídico, ou através de uma solene proclamação qualquer. Enraizadas nas práticas e na cultura das instituições e dos indivíduos, elas detêm, como mostra o caso moçambicano, uma capacidade de reprodução que vai muito além da vontade daqueles que sobre elas pretendem agir.

Com a liquidação do aparelho produtivo à vista, o governo acaba por garantir o apoio daqueles que deveriam ser os mais firmes opositores das privatizações: os trabalhadores e o movimento sindical. Em boa parte sustentada nas referidas relações de subordinação deste à Frelimo, verificou-se a total rendição dos sindicatos em relação às privatizações, contribuindo, assim, para o acordo entre o Estado, o capital e o trabalho sobre a destruição do aparelho produtivo nacional, engendrado pela aplicação das propostas neoliberais exigidas pelas instituições do Consenso de Washington. A prostração política e ideológica do movimento sindical servia à Frelimo e ao governo, ao assegurar a paz social mínima e a conservação do apoio de importantes segmentos da classe operária, tão necessário num momento em que se aproximavam as primeiras eleições 농 multipartidárias. No caso do caju, o mais im: portante setor industrial do país, o Sintic concordou com a reestruturação. Conhecedores da estratégia do governo, que, entre outros aspectos, condicionava o pagamento dos salários em atraso à conclusão do processo de privatização, os dirigentes sindicais foram mais

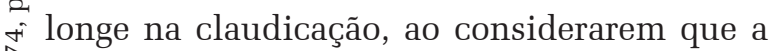
\& privatização se justificava no "quadro da dinâ今 mica econômica atual”, introduzindo somente $\overrightarrow{\text { a }}$ a ressalva da preservação dos postos de trabalho (Notícias, n. ${ }^{\circ} 22.912$ de 13/7/1994). Como precisou o então secretário-geral do Sintic,

${ }^{10}$ Realizado em 1990, essa posição, saída desse magno encontro sindical, é juridicamente sustentada pela lei 23/91 que, no seu artigo $7^{\circ}$, declara que as organizações sindicais são independentes e autônomas face ao Estado.
[...] a nossa posição era favorável à privatização [das fábricas], uma vez que elas nas mãos do Estado se encontravam obsoletas e praticamente paralisadas há mais de cinco anos. E sabíamos que o Estado não estaria em condições de fazer novos investimentos. Nós ficamos lesados com a privatização dos grandes setores econômicos. De certa maneira, este movimento de globalização aparece numa situação em que o país está bastante fragilizado. Mas estamos contra a rapidez com que o processo foi e continua a ser feito, sem proteção dos direitos dos trabalhadores. Moçambique não tem subsídio de desemprego (Boaventura Mondlane, entrevista áudio ao autor).

O Sintic foi incapaz de identificar o que efetivamente estava em jogo e, com isso, alterar a posição tomada, nem mesmo quando a Unidade Técnica para a Reestruturação de Empresas (UTRE) ${ }^{11}$ o afastou do processo, num momento em que ocorriam as privatizações das fábricas de Manjacaze, Inhambane, Machava e Chamanculo (Notícias, n. ${ }^{\circ} 22.765$ de 21/1/1994 e n. ${ }^{\circ} 23.025$ de 22/11/1994). As consequências são sentidas e reconhecidas:

Quando foi criado [em 1987] reunia 17.000 trabalhadores, a maior parte a trabalhar em empresas do Estado. Em 1995 é privatizado o setor, ano da introdução da liberalização da exportação de castanha, verificando-se atualmente uma situação caótica, com o despedimento maciço de 12.500 trabalhadores. Restam pouco mais de 1.000 no ativo. Neste momento o sindicato tem um novo desafio: acompanhar uma situação desastrosa e com poucos membros. Tudo isto é uma história triste. (Boaventura Mondlane, entrevista áudio ao autor).

As consequências foram devastadoras para o movimento sindical, colocando-o numa situação de fragilidade extrema. Porém, apesar das dificuldades e dos constrangimentos que a história e as instituições lhe impuseram, o movimento sindical moçambicano dá alguns sinais sobre o caminho que efetivamente almeja percorrer, quando, nos seus textos de reflexão, encontramos ideias tão fortes como a da "redistribuição do rendimento entre os grupos

\footnotetext{
${ }^{11}$ A UTRE é o órgão autônomo de coordenação do ministério das finanças moçambicano para a privatização das empresas estatais (v. www.tropical.co.mz/ $\sim$ parafirc/4_por.
} htm). 
sociais nacionais, e entre estes e o capital internacional”, recusando qualquer estratégia de curto prazo, sem prejuízo do engajamento em "lutas táticas diárias e pontuais [em prol da] luta diária para proteger o emprego e o salário real" (Documento de circulação interna da OTM-CS, s.d). ${ }^{12}$ Como faz o secretário-geral do Sintic, com uma lucidez e um sentido de classe quase surpreendentes, ao desejar que

[...] os sindicatos possam ter um papel, com outras organizações, no debate sobre alternativas ao atual sistema. Aqueles que declaram a morte dos sindicatos são aqueles que dizem que uma concertação global é suficiente. Adotando os princípios da OIT, em muitos países criaram-se as instituições tripartidas para criar um clima em que os interesses de classe não se coloquem com evidência. Mas eu penso que isso não vai ser possível. (Boaventura Mondlane, entrevista áudio ao autor).

Apesar dos erros, claudicações e fracassos, o movimento sindical prossegue com as suas lutas. Em 1999, a greve geral realizada foi uma prova de afirmação sindical, tendo contado com a solidariedade de parte da sociedade civil. Posteriormente, ao longo da primeira década do novo século, a OTM-CS tem apresentado à Assembleia da República moçambicana inúmeras propostas, muitas delas merecendo a oposição de deputados da Frelimo, posição que exprime a alteração da composição de classes no interior desse partido, com a entrada de membros da burguesia e a transformação de parte da antiga burocracia dirigente em nova burguesia.

${ }^{12}$ É certo, porém e em contraponto, que a prática está ainda muito longe do texto. Basta considerar, entre outros casos, o processo de constituição do comité sindical na unidade de Maputo da Shoprite, a grande cadeia de distribuição sul-africana, em que os dirigentes sindicais optaram por uma clara e escandalosa estratégia de alinhamento com o capital, apelando à contenção das reivindicações laborais dos trabalhadores, em particular salariais, sempre dependentes da melhoria da produção e da produtividade, segundo o entendimento dado pela entidade gestora (v. Vertical, n. ${ }^{\circ} 115$ de 22/7/2002). Essa situação não é nova, antes reproduz uma prática vinda dos tempos da Frelimo "marxista-leninista". Como justamente salienta Moyana (1993, p. 35), trata-se de um modelo que entende o sindicato como um "instrumento de dinamização da produção e produtividade da empresa", em que os comitês de empresa, nomeados de cima para baixo, "funcionam, na prática, como agentes ou representantes do patronato junto dos trabalhadores".

\section{CONSIDERAÇÕES FINAIS}

Em meados dos anos de 1980, num momento em que o bloco socialista se mostrava já incapaz de oferecer a Moçambique uma solução alternativa à crescente influência e à presença ocidentais, a elite dirigente abandonou definitivamente o projeto de um caminho relativamente autônomo em relação à economia -mundo capitalista. A penetração do capitalismo, ao mesmo tempo em que fere de morte as instituições preexistentes, transporta as contradições que se afirmam à medida que as desigualdades econômicas e outras se acentuam. Com elas, entrevê-se a propagação do conflito insanável que opõe, desde sempre, o capital ao trabalho, dominantes a dominados.

Trilhando caminhos bem conhecidos de outros países sujeitos a programas de ajustamento estrutural neoliberal, apresentados como fatalidade prescrita por quem tem força para prescrever, o patrimônio industrial foi alienado ao desbarato, sem que o Estado tenha conseguido cobrar as receitas legalmente estabelecidas e relacionadas com a sua venda. Quanto aos trabalhadores, no final desse processo, acabaram por não garantir nem os postos de trabalho. Em suma, o encerramento por atacado das fábricas, muitas delas recém-privatizadas, não compensado pela abertura de novas unidades, como se verificou no setor do processamento de castanha de caju, a destruição da base industrial produtiva e a redução da classe operária a um pequeno pedaço da que existia antes do arranque do processo são expressões concretas dos efeitos dos programas de ajustamento implementados em Moçambique (Ribeiro, 2010).

O fracasso do movimento sindical, na sua luta contra as privatizações, deveu-se, em boa medida, ao fato de a luta ter sido travada, sobretudo, contra os efeitos provocados pelo neoliberalismo e não contra ele. Nesse sentido, a ação sindical tem também de passar por um posicionamento crítico em relação ao partido Fre- 
limo, que voltou a ser, de novo, uma frente mas de uma natureza muito diferente. Já não é uma frente anticolonialista, com um objetivo preciso, a derrota do exército colonial português e a independência nacional, mas, a rigor, uma frente com uma enorme multiplicidade de interesses e classes sociais, na qual a burguesia, como classe, e o neoliberalismo, como ideologia, são hegemônicos. Apesar de existir um espaço razoável para a ação sindical, que poderá ser acompanhada por movimentos sociais saídos de determinadas franjas da sociedade civil, colocam-se dois grandes obstáculos que estão longe de serem novos: uma classe operária com poucos efetivos, sujeita a um desemprego brutal, o que funciona como um travão para o desenvolvimento das lutas no espaço da produção, e, por outro lado, uma população majoritariamente rural e escassamente escolarizada que, por tradição e necessidade, vive na dependência e é controlada por caciques locais, cuja legitimidade é fundada na autoridade tradicional, em reconstituição, e na autoridade eletivo-democrática.

De certo modo, o movimento sindical moçambicano terá de se refundar, forçosamente a partir da invenção de estratégias e práticas de antagonismo político e social radicais em relação à Frelimo e ao capital. O futuro dos trabalhadores em Moçambique dependerá lar$\stackrel{20}{\sigma}$ gamente da ação coletiva, introduzindo novas $\stackrel{\sim}{\circ}$ formas de solidariedade e cooperação com os $\dot{8}$ movimentos sindicais de outros países, em especial com aqueles que se situam na zona austral do continente africano, fundamentais para melhor defender os interesses dos que estão em baixo, nesse período conturbado do siste× ma mundial, em que, mais do que anunciar o \& seu fim, é um sinal forte de uma nova recon-

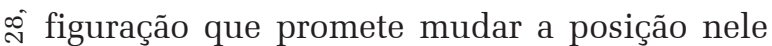
$\Rightarrow$ ocupada por alguns dos seus principais atores, os Estados-nação centrais, sem que quaisquer das suas principais contradições se apaguem.

Recebido para publicação em 04 de abril de 2014 Aceito em 17 de setembro de 2014

\section{REFERÊNCIAS}

ABRAHAMSSON, Hanse; NILSSON, Anders. Moçambique em transição: um estudo da história de desenvolvimento durante o período 1974-1992. Maputo: Paddrigu/ CEEI-ISRI, 1994.

BRINTON, Maurice. Os bolcheviques e o controle operário. Porto: Afrontamento, 1975.

DAVIES, Robert et al. Syndicalist struggle, class struggle and socialist transition: a case study of the Texlom textile mill. Maputo: CEA, 1980, (texto policopiado).

EGERÖ, Bertil. Moçambique: os primeiros dez anos de construção da democracia. Maputo: AHM, 1992.

HANLON, Joseph. Paz sem benefício: como o FMI bloqueia a reconstrução de Moçambique. Maputo: CEA, 1996.

HEDGES, David; ROCHA, Aurélio. A reestruturação da sociedade moçambicana (1938-1944). In (Coord.). História de Moçambique. Maputo: UEM, v. 2, 1999, p. 83-127. HILMARSSON, Hilmar T. Cashew pricing and marketing in Mozambique (second draft). Washington: Banco Mundial (World Bank Working Paper), 1995.

INTERVENCÕEES DOS DELEGADOS AO IV CONGRESSO. Maputo, 1985.

LEITE, Joana Pereira, A guerra do caju e as relações Moçambique-Índia na época colonial. Lusotopie 2000, p. 295-332, 2000.

LUXEMBURGO, Rosa. Questões de organização da socialdemocracia russa. In et al. Centralismo democrático. Coimbra: e.t., [1970 [1906)], p. 33-61.

MACHEL, Samora. Sindicatos organizarão os trabalhadores para matar a fome e a nudez. Maputo: Edições do Partido Frelimo, 1983.

MILANDO, João. O desenvolvimento participativo em contextos institucionais "adversos": aspetos africanos. Lisboa: Instituto Superior de Ciências do Trabalho e da Empresa, 2003, (tese de doutoramento).

MOYANA, Salomão. Problemas do sindicalismo em Moçambique. In: Sindicalismo em Moçambique: experiências e desafios, 1993, p. 25-37 (relatório e documentos de um seminário organizado em Maputo).

PITCHER, Anne. Sobreviver à transição: o legado das antigas empresas coloniais em Moçambique, Análise Social, v. 38, n. 168, 2003, p. 793-820.

RELATÓRIO DO COMITÉ CENTRAL AO IV CONGRESSO. Maputo, 1983.

RIBEIRO, Fernando Bessa. Entre martelos e lâminas: dinâmicas globais, políticas de produção e fábricas de caju em Moçambique. Porto: Afrontamento, 2010.

ROEMER, John E. A future for socialism. Cambridge: Harvard University Press, 1994.

ROESCH, Otto. Reforma económica em Moçambique: notas sobre a estabilização, a guerra e a formação das classes. Arquivo, 11, p. 5-35, 1992.

STALINE, José. Questões do leninismo. Vila Nova de Famalicão: e.t., [1972 (1926)].

STIGLITZ, Joseph E. Globalization and Its Discontents. Nova Iorque: W.W. Norton, 2003.

TCHÍRKINE, V. et al. O Estado de orientação socialista. Moscovo: Progresso, 1983.

WALLERSTEIN, Immanuel, $O$ capitalismo histórico (seguido de) A civilização capitalista. Vila Nova de Gaia: Estratégias Criativas, 1998.

Após o liberalismo: em busca da reconstrução do mundo. Petrópolis: Vozes, 2002.

WUYTS, Marc. Gestão económica e política de ajustamento em Moçambique. Estudos Moçambicanos, n. 8, p. 97-124, 1990. 
FROM REVOLUTIONARY EXHAUSTION TO LIBERALIZATION: the trade union movement in the face of privatizations in Mozambique in the 1990s

\author{
Fernando Bessa Ribeiro
}

The purpose of the article is to analyze the position of the trade union movement in Mozambique in the face of privatizations in that southern African country in the 1990s. Developing an argument strongly supported by history, an understanding of the inability of the trade union movement to oppose this process effectively must consider its trajectory in Mozambique since its origins, post-Second World War, and the trajectory of the country, particularly post-independence, characterized by civil war and the defeat of the revolutionary project. The data were collected through in-depth interviews with trade union leaders and political leaders and consultation of documentary sources files from Mozambique. As its main conclusion, this study indicates that the failure of the trade union movement, in its fight against privatizations, was due to the articulation of various causes, especially those related to its lack of autonomy in relation to the Frelimo, the "partyState”.

Keywords: Trade union movement. Privatizations. State. Politics. Liberalization.

\section{DE L'ÉPUISEMENT RÉVOLUTIONNAIRE À LA LIBÉRALISATION: le mouvement syndical et les privatisations au Mozambique dans les années 1990}

Fernando Bessa Ribeiro

L'objectif de cet article est d'analyser la position $\mathrm{du}$ mouvement syndical mozambicain face aux privatisations qui ont eu lieu dans ce pays d'Afrique australe dans les années 1990. On approfondit un argument fortement soutenu dans l'histoire, celui de comprendre combien le mouvement syndical a été incapable de s'opposer de manière efficace à ce processus. Pour ce faire, il faut tenir compte de son parcours au Mozambique depuis ses origines, après la deuxième guerre mondiale, et de celui du pays, en particulier après l'indépendance, marqué par la guerre civile et la défaite du projet révolutionnaire. Les données proviennent d'interviews approfondies auprès de dirigeants syndicaux et de responsables politiques ainsi que d'un relevé de documents d'archives mozambicaines. La principale conclusion à laquelle nous arrivons est que l'échec du mouvement syndical, dans sa lutte contre la privatisation, est dû à la conjonction de causes diverses, notamment de celles liées à son manque d'autonomie par rapport au Frelimo, "le parti de l'Etat".

Mots-ClÉs: Mouvement Syndical. Privatisations. État. Politique. Libéralisation.

Fernando Bessa Ribeiro - Doutor em Ciências Sociais. Professor na Escola de Ciências Humanas e Sociais da Universidade de Trás-os-Montes e Alto Douro. Pesquisador no Centro de Investigação em Ciências Sociais da Universidade do Minho. As dinâmicas do capitalismo e a mudança social em Moçambique constituem um dos seus principais interesses de investigação. Autor de numerosos artigos, livros, capítulos de livros, recensões e comunicações em atas, com destaque para: Entre martelos e lâminas: dinâmicas globais, políticas de produção e fábricas de caju em Moçambique, publicado em Porto pela editora Afrontamento em 2010; A terra dos heróis: espaço urbano e vida comercial em Manjacaze (Moçambique), em coautoria com José Portela, e, Chris Gerry, publicado na revista Análise Social, vol. XLIV (4. ${ }^{\circ}$ ), n. ${ }^{\circ}$ 193,em 2009; e Entre martelos e lâminas: dinâmicas globais e políticas de produção na indústria do caju em Moçambique, na revista, Dados, v. 51, nº2, em 2008. 
